\title{
A study on the Choice of B2C Cross Border E-commerce Logistics Mode
}

\author{
Bo Liu \\ English School, China West Normal University, Nanchong City, Sichuan Province, 637009, China
}

Keywords: Cross border e-commerce; B2C; Logistics mode; Foreign trade

\begin{abstract}
Cross border e-commerce logistics is a key link in the B2C cross-border e-commerce industry chain, but also a key factor affecting the success of small and medium-sized foreign trade electricity supplier, therefore, the study on the existing cross-border electricity supplier logistics model is of great significance for SMEs to choose cross-border e-commerce logistics model, reduce logistics costs, and improve corporate profits. Based on the author's learning and practical experience, this paper first analyzed the characteristics and key success factors of B2C cross-border e-commerce logistics, then compared the B2C cross-border e-commerce logistics model, finally put forward the B2C cross border e-commerce logistics model.
\end{abstract}

\section{Introduction}

As a representative of cross-border e-commerce, cross-border B2C e-commerce has been unanimously praised in the scope of international electronic trading market. In the continuous promotion and application of the national, the status of cross-border B2C e-commerce in China has gradually become unshakable, which plays a certain role in promoting the overall economy and foreign trade of our country. With the continuous development and improvement of e-commerce information technology in China, the development space of B2C e-commerce has been greatly improved under the overall influence of the whole environment. With the continuous construction of the network and the strengthening of international financial information exchange, the information flow and capital flow of cross-border B2C e-commerce have been strongly protected. At the same time, the development of the logistics industry has become a major constraint on the development of B2C E-commerce.

\section{The Characteristics and Key Success Factors of B2C Cross-border E-commerce Logistics}

Characteristics. The development of B2C cross-border e-commerce business is generally combined with the development of international logistics. For international logistics, it is often the special logistics activities of the national import and export trade, through the gradual formation of different logistics systems. This B2C cross-border e-commerce logistics process not only has a long journey and a long time, but has a relatively high risk. It needs to do a good job of customs clearance inspection and verification of international trade, and do a good job in logistics insurance business application.

Key Success Factors. The key success factors of B2C cross border e-commerce logistics are shown in Figure 1. The quality of customer satisfaction and product delivery cycle has a direct correlation with the payment security. For cost performance, customers not only have higher requirements for the quality of goods, but also pay attention to the delivery time and service costs of goods. As for information feedback, it is necessary to pay attention to the effective guarantee of the quality of goods, timely provide accurate logistics tracking information, and constantly increase the transparency of information. 


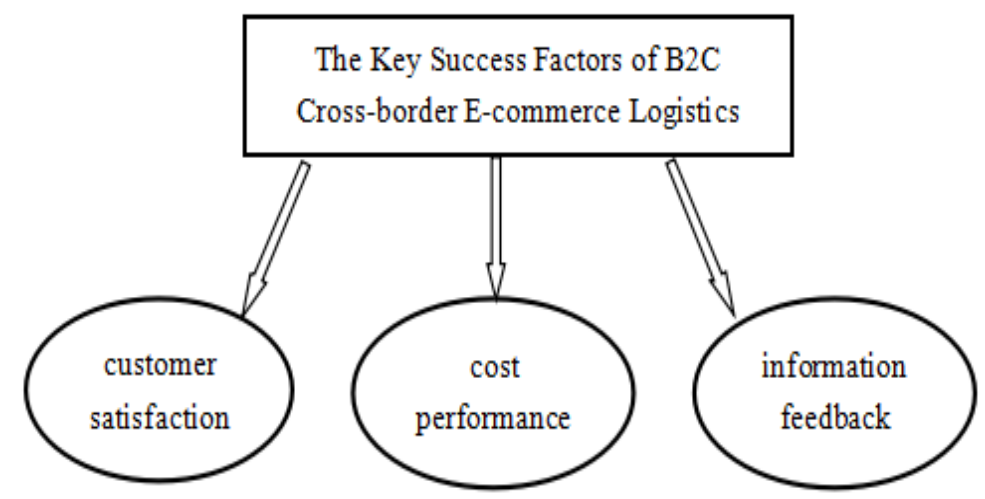

Fig.1 Key Success Factors of B2C Cross-border E-commerce Logistics

\section{Comparison of B2C Cross Border E-commerce Logistics Modes}

Self operated Logistics. Its cost has a large investment in the early stage, and has a very low operating cost in the late stage. Because the proprietary model is a self built enterprise system, it has better stability. It is easy to control, so it can be upgraded and provide personalized service for customers. Enterprises have the right to control the logistics system, so it has a higher level of information sharing, to plan for the transportation routes with lower fuel consumption.

Sharing logistics. Using integrated resources, it has a higher resource utilization and lower cost. Because B2C and traditional business sharing has a poor stability, the traditional logistics is easy to impact on it although the sharing mode is convenient to control.

The third party logistics. With the division of labor and specialization, the logistics cost is very low. Usually, enterprise and third party logistics companies have no stable cooperation, so, it is difficult to provide personalized service. The logistics of the third party contracting enterprises has a low level of information sharing, and it can make full use of the existing resources, so it has lower fuel consumption

The logistics alliance mode. This mode is established by the alliance with low cost. The construction of alliance relationship is for common interest, but it is with poor stability. The service project and requirements can be negotiated. At the same time, it has low level of information sharing, and the transportation routes cannot be better planned because of differing opinions between coalitions, so it has higher fuel consumption.

\section{The B2C Cross Border E-commerce Logistics Model}

International packet. International packet has many advantages, such as: low transport cost, simple billing, unrestricted sending place, but hit also has some shortcomings, such as: long transportation time, difficult tracking of goods, and high packet loss rate. International bags are suitable for the goods whose weight is less than two kg, the sum of length, width and height is less than 90 centimeters. This mode is suitable for the products of small volume, light weight, electronic products, cheap jewelry, clothing accessories.

International express. The advantages of the international express delivery are: the delivery speed is faster, the goods safety and service quality is relatively high, and it can facilitate the tracking query. The disadvantage is the high cost of logistics. Logistics network distribution of the international express company is different, and they each have different competitive advantages in different regions. The seller must understand the advantages of regional distribution various courier companies, in order to save the cost of express delivery. For example: the United States and Canada usually use UPS, Eastern Europe usually uses TNT, South America usually uses FedEx. For the 
more remote areas, we can choose EMS, because the EMS all is over the world, so it can realize the global distribution. This model is mainly suitable for the products with higher requirements on the aging value and profit.

Overseas warehousing. As the goods have been shipped to the buyer's country by sea or air, so we can directly inform the cooperation of logistics distribution of goods abroad when the seller received orders, in this way, we can greatly shorten the time the buyer receives the goods, easily won the favor of buyers and improve their satisfaction. But this model has shortcomings - The cost of construction and daily operation cost is high. Overseas warehousing needs a greater construction funds, generally speaking, overseas warehousing is conducted by the cross-border business enterprise with many power, but they nearly not open to small and medium-sized business enterprise, so the overseas warehousing currently cannot realize the sharing of resources. Since 2014, the number of overseas warehousing is increasing in Europe and other mature markets of cross-border electricity supplier. Due to the continuous upgrading of cross-border electricity supplier category, some heavy and large volume of goods, such as furniture, appliances and automotive, their export is more and more through electronic business platform. The cost of air distribution is very high and the ocean transportation time is too long, so, usually the goods transported by sea to overseas warehouse in advance. In addition, some cross-border e-commerce platforms encourage sellers through overseas warehouse to distribute goods. The distribution model is mainly applied to seller with a relatively strong financial strength and goods with high value, strong ability to bear the cost of logistics and relatively stable prices.

Large scale transportation after agglomeration. The advantage of cross-border foreign trade enterprises is to use economies of scale effect, so the logistics cost is relatively low, but the early logistics warehousing capital investment is large, and the operation and operation are complex. Therefore, the model is suitable for cross border electricity supplier foreign trade enterprises with large scale and high order. Alliance gathering goods of cross border foreign trade enterprises can reduce logistics costs, but it is difficult to coordinate the content management of strategic alliance, so it is not widely used in practical promotion. Compared with the above two kinds of logistics mode, third party logistics and warehousing logistics have many advantages. Whether it is cross-border e-commerce platform collection or international logistics company cargo collection, the foreign trade enterprises do not need upfront warehousing logistics investment, but it can achieve rapid concentration of orders goods, so the third party logistics warehousing cargo is a good choice for most cross-border foreign business enterprise at present. At present, the existing cross-border electricity supplier logistics model has its advantages and disadvantages, among them, logistics cost is the most influential factor in the selection of logistics mode of SMEs. Postal parcel risk is larger, and unit freight is higher; International express has a high speed, and safe transport, but the freight is very high. International packet and international express are the general logistics mode used by cross border foreign trade enterprises. International packet and international express are the logistic mode that the current cross-border foreign trade e-commerce used. As for the products that the order amount is small with low single frequency and remote market, the seller can choose ordinary express or by third party logistics like warehousing logistics. As for the products that the order amount is large with high single frequency, they can choose in accordance with the actual situation and the advantages of different logistics modes.

\section{Conclusion}

B2C cross-border e-commerce logistics management model is not only directly related to the transaction costs of foreign trade enterprises, but also related to the satisfaction and trust of foreign buyers to foreign trade enterprises. It is also related to the customer's shopping experience, and then related to the seller's sales performance and final earnings. Therefore, the B2C e-commerce enterprises in Chengdu must choose the most appropriate logistics mode according to their own financial strength and product nature, so that to promote the development of cross-border e-commerce. 


\section{References}

[1] Qian Huimin, He Jiang. Empirical Study on Choice of B2C Cross-border E-commerce Logistics Mode[J]. Business Research, 2016,12:118-125.

[2] Dai Jiyuan. Analysis on the Choice of B2C Cross-border E-commerce Logistics Mode in China[J]. Business Economy, 2017,08:65-66.

[3] Fan Xiaoyun. Research on B2C Cross-border Foreign Trade E-commerce Logistics Distribution Mode[J]. Journal of Pingxiang College, 2015,01:26-29.

[4] Zhang Yu, Li Qi. Research on Choice of B2C E-commerce Enterprise Logistics Distribution Mode [J]. Human and Culture journal, 2012,03:187-193.

[5] Wang Lepeng, Liu Xuan, Zhang Shixiang. Research on B2C Cross-border Foreign Trade E-commerce Logistics Distribution Mode[J]. Business Economy, 2012,17:44-46.

[6] Zhao Mengli, Wang Ting. Study on the Choice of B2C E-commerce Logistics Mode--Taking VANCL as an Example[J]. The National Business (Theory Research), 2012,19:27-28.

[7] Hong Shujuan. Choice of Logistics Mode of Large B2C E-commerce Enterprises[J]. Science and Technology Economic Herald, 2016,10:44. 